\title{
17. Learning about Change Through Industrial Open Innovation in the Fast-Moving Consumer Goods Sector
}

\begin{abstract}
Sarah Pearson
Whilst some of us thrive on change, many people find it threatening. Tension between the Darwinian drive to evolve and our social need to fit in with the status quo plays out in industry just as much as in our individual lives. In no situation is this more obvious than the role of innovation within industry, where innovation is change and often requires us to change just as much as the product or process that is being replaced. Us as employees, and us as consumers. This chapter gives an insight into how industry thinks about change, particularly relating to innovation within the fast-moving consumer goods sector. It also presents two case studies demonstrating how competitive market pressure has driven changes in innovation practice, especially encouraging open innovation. The second case study which stems from my own experience also demonstrates how to overcome the understandable internal inertia that blocks successful change, and how to work with failure.
\end{abstract}

\section{Innovation as a microcosm of industrial change}

When considering change in an industrial setting, one needs to be aware of the tensions that exist: tensions between corporate and individual needs, as well as between the long-term survival of the company and the need to demonstrate short-term success. The process of innovation heightens these tensions, requiring short-term actions to drive long-term commercial success, sometimes requiring change before the need is obvious, and flavoured with the inherent risk of failure and hence threat to individual careers. This is all assuming that consumers are driving the need for change. Throw in consumers who may also need to be encouraged to change if the driver is technological advances, even when the benefits are obvious, and you have a real challenge on your hands. 


\section{Innovation}

Innovation has many definitions. For the purposes of this chapter I describe it as:

Change that delivers value.

Value could mean the delivery of new products, new services, and new processes that improve profit through increased revenue, or cost reduction.

In spite of these tensions, innovation plays a key role in the long-term survival of a company, with innovative and collaborative companies consistently outperforming their counterparts. Globally governments have recognised this and put numerous programs in place to support innovation. But even with this recognition of its importance, and government support to encourage it, innovation is not a simple activity to embed.

\section{Challenges for industrial change}

Whilst industry is often portrayed as an unemotional and logical entity, this is merely a macroscopic view. Our legal system reinforces this through corporations law, where a company is given rights and responsibilities as if it were an individual, with stringent implications when that 'individual' either fails to comply with the law or fails to succeed. The company is assumed to have a long-term future, and its leaders are expected to make decisions in the shortterm to secure this long-term success.

However, if a company is no longer able to pay its bills, it is no longer allowed to trade, and effectively ceases to exist. This leads to the sense that a company will do all in its power, in a strategic and logical manner, to survive. It also encourages a culture of risk-aversion, since the consequences of failure can be dire.

Yet companies comprise people: people with fears and ambitions, preconceptions and views of self that have been built up over years of experience, outside the work environment as well as inside it; people without access to the entire information set ideally needed for strategic decision-making. Nor will all of their individual decisions be obviously logical, unemotional or aligned to long-term 
company survival. Hence when attempting to understand and drive industrial change, one must take into account the individuals, with all their individual strengths, commitment, and foibles.

With this in mind it is fairly simple to identify a number of reasons why industrial change is challenging and is seen as a threat by individuals, including these:

- In the short term, change requires energy. This can be daunting, even if the long-term gains are obvious. Rather like in a chemical reaction, a catalyst is often required to encourage people over the 'activation energy' barrier. People need a reason to put in this energy - what is in it for them?

- Change can also be perceived as a threat to people's jobs and sense of self-worth in the workplace. Change invariably raises the thought that something must be wrong now in order to require this adaptation. When employees base their self-image on success in the workplace, change that implies that they could be doing better is challenging. People need to see how the change will help their self-image.

Next I present two case studies of driving change in industry, outlining ways in which these and a number of other challenges can manifest, and suggesting actions that can be taken to overcome them. Each case study is based on experience working in industrial innovation, where change was necessary to improve productivity and competitive positioning.

\section{Case Study 1: Competition as a driver of open innovation}

In the fast moving consumer goods sector of today's world, the rate of product innovation is so rapid that companies have to adopt new approaches to product development in order to remain competitive. The old linear approach, involving the sole use of internal research and development (R\&D) teams, no longer delivers new products at a sufficiently rapid pace to keep up with consumer demand or competitor supply.

Consider the frequency of new product launches in the electronics industry, or the personal goods sector. How can a company keep up with this pace using only internal R\&D groups, its own ideas? Something has to change in the way organisations develop new products in order to meet this acceleration and stay in the competitive game. This competitive driver is proving a strong catalyst for change. 
In order to react to this competitive environment, companies are looking outside their organisational boundaries for new ideas, new products, or solutions to current technical challenges in order to speed up their innovation process. Rather than devoting years to solving technical challenges or developing new products themselves, companies are realising that a more efficient approach is to seek external partners who have either solved the technical challenges, or developed new products already. This speeds up the process to product launch, and helps the company to grow more rapidly. This is termed by most as 'open innovation'. ${ }^{1}$

\section{Open innovation example}

Proctor \& Gamble employs a connect + develop $^{\text {SM }}$ program of activity, devoted to sourcing new product ideas from outside the company globally. By looking outside the company Proctor \& Gamble are able to launch new products without spending many years on development themselves.

The face cream product Olay ${ }^{\mathrm{TM}}$ Regenerist, for example, did not come wholly from Proctor \& Gamble R\&D teams, but involved sourcing technology already developed by a small French company (Sederma). A partnership was formed between Proctor \& Gamble and Sederma, and this product is now sold around the world within Proctor \& Gamble's broader brand portfolio. The partnership meant that Proctor \& Gamble saved years of development work, getting a new product to market fast. For Sederma, it allowed access to global routes to market that would have taken many years to develop themselves.

Large successful companies, such as Proctor \& Gamble, General Mills, and Cadbury, have turned to this new model for innovation in order to beat their competition and drive improved corporate growth. Yet whilst open innovation is a logical, efficient and effective method for innovation, without the threat of competition most companies would not consider making the necessary changes for fear of having to deal with their associated challenges.

\footnotetext{
1 Open innovation differs from outsourcing. In outsourcing the organisation looks for another organisation to provide a service that it no longer wants to deliver itself (such as cleaning). In open innovation, the organisation seeks solutions to its challenges, or new product ideas, externally, which may lead to contracting research, collaborative projects, joint ventures or simply purchasing the technology, business or idea.
} 
Proctor \& Gamble, considered to be global leaders in open innovation, represent a classic example of how competitive pressure led them to take on the challenges of this change in innovation practice. During the year 2000, Proctor \& Gamble reported several profit warnings. Some of their leading brands had weakened and their competitors were making the most of this. The market lost confidence in the company, leading to a severe downturn in the share price: the stock price dropped 50 per cent over the six months from January to June. Something had to be done. The energy for change had to be found.

The company's new Chief Executive Officer, AG Lafley, realised that in order for the company to rise above this challenge it needed to put innovation at the centre of all that it did. Why? Because it needed to return to high growth rates, achieved through the delivery of new products and new markets - fast. When you are an $\$ 80$ billion+ company, growth rates above a few per cent pose significant challenges in a competitive environment. Hence not only did something have to be done, but something different had to be done. Lafley turned to open innovation.

To speed up their innovation process and hence shorten the time to launch new products and enter new markets, Proctor \& Gamble were forced to look outside for new technologies and ideas. The new approach has paid off. Thirteen years on and Proctor \& Gamble have developed more than 2000 global partnerships, delivered dozens of global game-changer products to consumers, accelerated innovation development and increased productivity, both for Proctor \& Gamble and its partners.

While competition is a key driver of this change, there are other exogenous changes that make it a sensible strategy, such as the change in distribution of $\mathrm{R} \& \mathrm{D}$ spending beyond the traditional concentration in large multinationals to being spread over a large number of small companies; and the connectedness of our society making it so much easier to connect to people and ideas on a global scale, rapidly. So it is not merely a need driven by competition, but an opportunity driven by a growth in ideas being generated in numerous organisations and the ability to connect to them. 


\section{Speeding up the innovation process}

When looking for new ways to invigorate the Pringles brand, Proctor \& Gamble came up with the idea of printing images on potato crisps. They soon realised that they needed to look externally for ideas of how to print edible dye images on potato crisps. Their open innovation team discovered a bakery run by a university professor in Italy that had developed a way of printing edible images on cakes. A few small changes were required to adapt this technology for Pringles, but they were able to launch Pringles Prints in just eight months compared to the usual two years. Within one year, the new product grew Proctor \& Gamble's revenues 14 per cent, extraordinary for such a large company.

The new approach has proved incredibly successful, so much so that many companies around the world are implementing it and learning from Proctor \& Gamble's experience. However this did not happen overnight and required significant change in behaviour, and the experiences of strong barriers to change, and threats to individual perceptions of self-worth. The next section outlines some of these challenges through a case study of starting up an open innovation approach at Cadbury plc.

\section{Case Study 2: Overcoming internal barriers to open innovation}

Cadbury plc started to look to open innovation as a tool to enhance innovation productivity in late 2006. The Chief Technology Officer at Cadbury initially drove the change, drawn to the idea through competition: a number of his colleagues in other companies had started to adopt the strategy, including Cadbury competition.

The company soon came to realise that open innovation could accelerate their innovation process and provide access to new ideas the company would not have dreamed of on its own. Not only did they believe that no one company can own all the world's best scientists, but also that solutions to technical challenges could already exist in non-competing industry sectors.

This challenged the embedded approach, where expert scientists were hired to work on technical aspects of new product development, priding themselves (quite rightly) on their technical expertise and contribution to the company's goals. These experts saw themselves as the best in their field - why would they 
need to look outside for ideas? What did it mean for their own self-worth? Some had also tried looking outside for ideas in the past and it had failed: 'Well, we tried that once before and it hasn't worked. Why would we bother again?' We needed to be able to say 'How can I help you achieve your goals and make you look good?', and 'Okay, well perhaps that didn't work in the past, but here's something that has worked for you now.'

A pilot project was used to kickstart the new innovation activity. It was so successful that a small UK-based team was set up with a global remit to develop an implementation strategy, grow capacity, develop an open culture, and deliver value through sourcing technology solutions and new product ideas from broad areas outside confectionery. I helped out with the pilot project, and subsequently took on the lead role driving the change across the company globally. I set up a small UK-based group that quickly evolved into a globally linked open innovation team, strongly embedded internally and externally and aligned with global category strategies.

Over an 18-month period a list of global technology needs was agreed with the business; more than 60 searches for different needs were conducted, with licensing, collaboration and co-development projects initiated globally. In addition, numerous patents were granted, non-food technology was identified for a novel product platform, and the development of an open culture led to external partner involvement in half of the long-term research projects. Cadbury received recognition as innovative leaders and external parties began to approach us with ideas.

How was this change in approach driven? What were the keys to this success? There were many well recognised keys, such as strong leadership support (from the Chief Technology Officer initially, and after a short period the Chief Executive Officer too), a dedicated team, and appropriate resources. As the head of open innovation, I was also given the title 'Open Innovation Champion', signalling the importance of this new approach to the rest of the company globally.

In addition we came to understand the following keys to success:

- the critical importance of delivering value in early stages

- the need for ownership and trust

- building cross-functional and integrated support

- working with failure. 


\section{Early value delivery}

When I took on the role of open innovation champion I looked for literature discussing the mobilisation of change, to help shape how I would go about implementing this challenging new approach at Cadbury. I was pretty unsuccessful in finding what I needed, but I did come across a publication suggesting that successful change is led by results. Promising results before implementing change can work, but starting with results is even better. This was instrumental in my strategy, and I later found that others leading open innovation had experienced the same.

By demonstrating early wins, getting others on board and encouraging them to embrace the change is much easier. People see the reason for change. There are several ways of ensuring this, one being the use of an 'under the radar' pilot project to test out the change. The other (which can be combined with the first) is to start with 'low hanging fruit' - focusing on a challenge for the change process where you are sure an impact can be demonstrated.

At Cadbury, the six-month pilot project was run quietly inside the long-term $R \& D$ centre in the UK. A few key supporters outside the centre were involved, but the project was not highlighted around the company. Two technical challenges important to the business were chosen, and broad searches for solutions outside the company sought.

We found several promising solutions for these challenges. A novel technology used for pressure sensors in sails, with the potential to provide a new product platform in all three categories (chewing gum, candy and chocolate) was also discovered fairly quickly. Demonstration of this early success led to buy-in, support and resources from the R\&D leadership level within the company.

The next step involved rolling the new process out across Cadbury globally. In order to encourage people to change, to overcome the cultural and energy barrier to looking outside for ideas and the perceived threat to their capability and self-worth, this early win was used as a tool to demonstrate how powerful the new approach could be.

The major lesson in this process was that the early win had to be more than just an idea. People needed to be able to see and touch the new product. It needed to be tangible and its value obvious. Prototype products were made, designs drawn up, and templates outlining the impact on and benefits to the business developed. These were then shared and communicated globally around the business, with leaders and those below them responsible for project delivery. 
The key here was to learn and speak the 'language' that helped demonstrate the value. The appropriate language for most was that of a tangible product. For others it related to bottom line impact, such as an indication of market size and likely revenue as well as brand impact.

By showing employees the early win and making sure that they could see how we could help them deliver new products and solve their technological challenges, we got widespread support and involvement. The early win acted as a catalyst for change, giving people the reason, or impetus, to overcome inertia and consider trying out the new approach.

\section{Ownership and trust}

The second and most important key to success was the need to demonstrate without a doubt that we were there to help employees and the company achieve their goals - that we were not in competition, not simply a fad, but there to provide support and that we were not a threat to experts, but there to help them achieve their goals. New product development teams had tight deadlines to meet regarding product launch. The open innovation team needed to show that we were there to help them speed up development, so that they could reach their targets effectively and at times more efficiently.

In order to achieve this, part of the strategy for growing the open culture across Cadbury involved ensuring that the open innovation team searched for technology that would directly assist the new product development and R\&D teams with their product development plans. I had seen a number of companies failing in their open innovation activity when their external searches were not linked to internal company needs. They would be sent out to 'find something interesting', and like the cat coming home with the mouse, discovered that what they found was not what the company wanted.

In order to avoid that outcome, we asked the new product development and R\&D teams to help compile a needs list, a list of technologies that they would like us to access. The open innovation searches were aligned to this list, ensuring that they were owned by the new product development and R\&D teams.

This played three important roles:

- involvement and ownership of the open innovation process by the new product development and R\&D teams. This helped reduce the threat to their self-worth as they were in the driving seat, with us helping them to find ways to deliver to their targets faster and hence leading to greater success for them 
- the knowledge that if technologies were found that met the identified needs, they would be seen as valuable, thereby reinforcing the value of open innovation

- ensuring that when technologies were found they would be brought into Cadbury and used in new products. This helped deliver success through the open innovation process, as well as giving external collaborators the confidence that their technologies would be used.

Ownership of change can also be encouraged through appraisal systems. Whilst the usual incentive systems play to short-term results and rewards, key performance indicators can be devised that help to guide behaviour change for longer term benefits. Companies can assess short-term steps that will support the long-term change, and reward employees for taking these steps.

For instance, each employee at the Cadbury R\&D centre was given roles, responsibilities and goals to reach over the course of 12 months. A range of key performance indicators were used to assess achievement of these goals, with bonus payment being related to these. Each member of staff had one indicator related to their open innovation activity in order to help grow the culture and focus, thereby supporting ownership and engagement with the overall strategy as it grew.

Whilst in the early days of this activity some of it would not be successful, the key performance indicators were designed to encourage at least trying this new approach. Before we started the program, only a handful of long-term research projects involved external partners. After a year of applying the key performance indicators, and supporting the open innovation activity, half of the long-term research projects involved collaborations with external partners. Most employees had at least considered whether looking outside would yield productive results.

Another barrier to widespread engagement with open innovation is the issue of confidentiality and trust. How can you safely share information externally with other companies, knowing that your competitors could access the information? In the past, innovation has been kept securely within corporate boundaries as companies are justifiably concerned that their competition will use any information on new product ideas and technologies to inform their own strategic planning. Trust and appropriate processes need to be built with employees before they will be convinced to change their behaviour and start to talk with people outside the company, including in some instances their competitors.

The way that we addressed this was to build trusting relationships with each employee who had a need to seek external technologies, work alongside them to decide whether or not the information was too sensitive to be able 
to share externally in any form, and then define and agree a non-confidential description of the technology or science that we could share with external parties. We developed a process of sharing the descriptions with them, having them check that we had understood correctly and reinforcing that this was their search, to help them, in a safe way.

By working closely with the new product development and R\&D employees, we were able to build confidence that we would act in their best interest and with care to find the external technology that they required, without jeopardising the project. This led to confidence in the open innovation team and process, thereby encouraging greater support and involvement.

\section{Cross-functional, integrated support}

When considering change within a company, thought needs to be given to who needs to be drawn into the change process. At an early stage in the Cadbury process it became clear that we needed to reach out to more than just the new product development and R\&D teams. Marketing functions tend to drive product launch decisions in the fast-moving consumer goods sector, making it important to reach out to them as well for driving change in the innovation process.

In order to bring them 'onside', I spent considerable time working with the marketing groups, building trust, explaining the new approach, and demonstrating how we could help them achieve their launch goals. Again the quick early wins helped establish the potential of open innovation to help marketing groups reach their goals of launching competitive products.

As with the R\&D groups, we asked marketing employees to help us compile a needs list that would be used to guide the open innovation searches. Once this was completed, we had a list of technologies to look for that linked to real needs within the company, from the new product development, R\&D and marketing teams.

The efforts of the open innovation team were split approximately 80:2080 per cent of our efforts were dedicated to delivering solutions to the known R\&D challenges, thereby reducing time to market; and 20 per cent were dedicated to finding new technologies that could meet a consumer need or give Cadbury a dramatic commercial advantage.

We also made sure that we were open to serendipitous finds: we were frequently approached by organisations with good ideas, or we stumbled across interesting technologies during our networking. In order to help filter these ideas we 
worked closely with the marketing and consumer foresight groups to gain an understanding of consumer trends and commercial strategies. Selling these novel ideas internally would have been very difficult without a good understanding of the marketing strategy and long term consumer needs, and strong relationships with the global marketing teams.

Whilst it was a major advantage to have reached this stage, it soon became clear that it was a piecemeal solution. My vision was to incorporate open innovation into a multifunctional approach, involving employees from a range of groups such as new product development, $\mathrm{R} \& \mathrm{D}$, marketing, legal and manufacturing areas within Cadbury. We developed a method for identifying and agreeing medium term technology needs with integrated multifunctional involvement, followed by a decision process about whether to make internally, buy from outside, or partner to co-develop the necessary technology. In this way open innovation was integrated into global innovation strategy setting, in a multifunctional process, having managed to deliver change across company functional boundaries.

\section{Working with failure}

Whilst I have talked mainly of success so far, it is important to consider how to deal with failure when it occurs, as well as how to mitigate it when designing successful change programs. If there is no failure, then arguably there has been no innovation. How do you accept and work with failure whilst acting to maximise success?

The practical approaches described above were developed in order to mitigate failure, as well as to maximise success. For instance, knowing that siloed R\&D activity would not help in terms of taking ideas to market, I involved crossfunctional teams and worked closely with the power brokers in marketing. If I came up with ideas on my own, who would listen? Why would they listen? But if I had had people working with me to come up with that idea, there was a much bigger chance that the process was going to be successful.

We also worked on several external searches at a time, running a portfolio of projects so that if one failed, at least we would have other success stories to tell. When an idea failed to be accepted by the company, we kept a record of it in case it was merely a timing issue. Quite often ideas that are rejected one day are accepted another when strategies and markets change. And finally, if an approach did not appear to be working, we stopped doing it quickly and tried to learn from our failure - the 'fast failure' approach. 


\section{Conclusion}

Change is hard. It requires energy and a compelling reason to jump on board: energy from those leading change, and energy from the followers. In spite of the widespread sense that companies are ruthlessly focused on success, industry is not immune to this challenge, even when the need for change is obvious. However, the drive to remain competitive can provide the energy to help individuals and organisations accept new ways of working and delivering value.

Industrial innovation, a microcosm of change, is itself innovating. Innovation is accelerating. Companies are being forced to adapt and innovate more and more rapidly as their customers demand new products and services with a voracious appetite, and competition finds ways to deliver fast. This is forcing them to learn new ways to energise their employees, to embrace new approaches, new business models, new products and services, new processes.

This chapter has discussed a number of approaches used successfully in industrial change programs, specifically related to industrial innovation. Key insights to consider from this experience include the obvious, such as supporting champions to lead change, and demonstrated support from the top. As well as this, experience has shown that quick wins, a service approach to showing how the change can help employees achieve their own goals, gaining buy-in from a range of stakeholders across institutional boundaries, and working with failure can greatly enhance successful growth of change uptake. 
This text is taken from Change! Combining Analytic Approaches with Street Wisdom, edited by Gabriele Bammer, published 2015 by ANU Press, The Australian National University, Canberra, Australia. 